\title{
Correction to: Patient's view on better care
}

\section{Jette Kristensen ${ }^{1} \cdot$ Manuela Brösamle ${ }^{2}$ Bas van den Berg ${ }^{3}$}

Published online: 17 March 2021

C Springer Science+Business Media, LLC, part of Springer Nature 2021

Correction to: Endocrine

$$
\text { https://doi.org/10.1007/s12020-021-02653-w }
$$

The author of the article want to include the graphical advertisements in this article.

The graphical advertisement is given below.

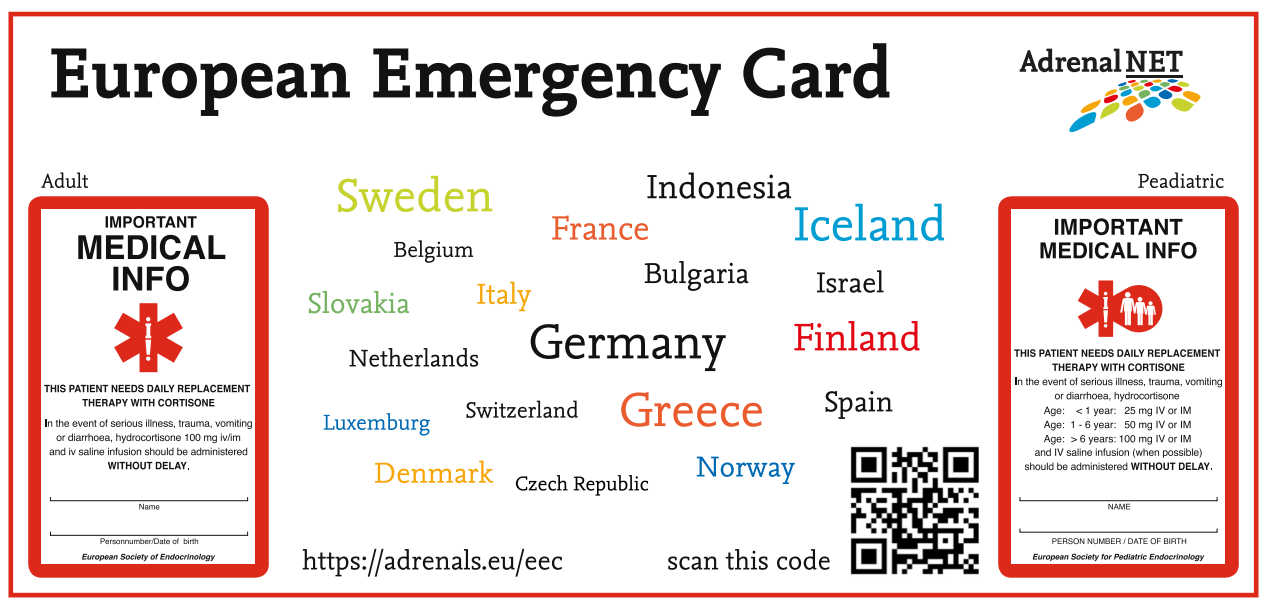

The original article has been updated.

The original article can be found online at https://doi.org/10.1007/ s12020-021-02653-w.

$\triangle$ Jette Kristensen JETTE@ADDISON.DK

1 Addison Foreningen i Danmark, Skodstrup, Denmark

2 AGS-Eltern- und Patienteninitiative e.V. Germany, Kötz, Germany

3 Dutch Adrenal Patient Society NVACP, Nijkerk, The Netherlands 